\title{
Tensile tests of specimens made of selected group of the filament materials manufactured with FDM method
}

\author{
Cezary Grabowik ${ }^{1, *}$, Krzysztof Kalinowski ${ }^{1}$, Grzegorz Ćwikła ${ }^{1}$, Iwona Paprocka $^{1}$, and \\ Pawet Kogut ${ }^{2}$ \\ ${ }^{1}$ Silesian University of Technology, Faculty of Mechanical Engineering, Institute of Engineering \\ Processes Automation and Integrated Manufacturing Systems, Konarskiego 18A, Gliwice, Poland \\ ${ }^{2}$ 3DGence, Konarskiego 18C, Gliwice, Poland
}

\begin{abstract}
This paper presents results of tensile tests carried out for specimens made of the selected group of the filament materials. As a manufacturing technology FDM 3D printing method was chosen. The selected group of the filament materials involved the group of wood, PLA, ABS, PET, PMMA and ASA. Herein, it should be noticed, that technical data sheets that are delivered by filament materials producers include data that are valid for only one specific printing direction. This printing direction is deliberately selected, in such way that ensures the best material characteristics. Therefore, received during the research results allow to make comparison between a catalogue data and data obtained in the printing process. It aids both mechanical designer and product manufacturer at the stage of the printed product mechanical properties shaping.
\end{abstract}

\section{The selection of the materials subjected to the tensile test}

Currently, a vast variety of materials is available on the market. This group of materials is called filament. Filament is a thermoplastic material. It is wound on the spool in the form of a thin wire. Typically, the spool contains $1 \mathrm{~kg}$ of a material. In our case, $1.75 \mathrm{~mm}$ diameter filament was used. Manufacturers of the filament are constantly trying to surprise clients with new materials. A few years ago, only ABS or PLA were in the offer. Nowadays, these materials are the basis of FDM technology and they are the most popular. Newer and newer materials are commercially available. For example, materials with admixtures of wood or chalk, which were created for design applications. On the other hand, the impact of the industry has demonstrated a need for materials for engineering applications, such as ABS, ASA, Nylon, PET, PMMA or rubber. Above the basic properties of the selected materials are given.

3DGO Wood is a product name of the material made by 3DFilamenty Company. The original name of this filament is LayWoo-D3 or LayWood and it was created by Kai Parthy from CC-Products Company [1]. This filament consists of $60 \%$ of PLA which is the base of this filament and $40 \%$ of wooden powder which is an admixture. The material has a wood

${ }^{*}$ Corresponding author: cezary.grabowik@polsl.p1 
color and it smells like wood during printing, that is why, it is ideal for printing elements imitating wood [2]. Printouts can be easily machined, sanded and painted. The manufacturer guarantees that the material is biodegradable, does not deform or warp during printing and is easy to print with low temperature of the hot end. The recommended temperature of the hot end is between 205 and $230^{\circ} \mathrm{C}$ and temperature change results in different shade of a printout. The admixture of wooden powder causes the decrease of the melting point (compared to the standard PLA). The tolerance of the filament diameter is equal to $\pm \varnothing 0.05 \mathrm{~mm}$ and the roundness is $95 \%$. Print settings are similar as in case of PLA, but the temperature of the hot end can be lower. In this case, $95 \%$ of material flow was used and temperature of print head was equal to $212^{\circ} \mathrm{C}$ on the first layer and $210^{\circ} \mathrm{C}$ on others. Initially, the cooling fans were turned off. From the third layer it was set at $50 \%$ and from fifth layer to the end of printout it was set at $100 \%$ of cooling. This material can be printed a little bit slower than $35 \mathrm{~mm} / \mathrm{s}$ to obtain a much better quality of the printouts.

PLA - polylactide is a biodegradable thermoplastic material. PLA is one of the most popular materials in 3D printing (FDM). Its popularity is gained due to the low price, satisfactory strength and ease of printing as a result of material's low shrinkage. PLA made by INK3.de was used to prepare the samples. The density of PLA is equal to $1.24 \mathrm{~g} / \mathrm{cm} 3$. The recommended temperature of the hot end is between 180 and $210^{\circ} \mathrm{C}$, but the melting temperature is $210^{\circ} \mathrm{C} \pm 10^{\circ} \mathrm{C}$. The tolerance of the filament diameter is equal to $\pm \varnothing 0.05 \mathrm{~mm}$ and the roundness is $95 \%$. PLA can be printed without using the heated bed but it is suggested to use it because this increases the adhesion of the print to the table. The typical value of MFI (Melt Flow Index) is equal to $6.0 \mathrm{~g} / 10 \mathrm{~min}$ [3]. PLA has a low shrinkage factor so it does not deform or warp after strong cooling. That is why, the first three layers of the samples were made without cooling, whilst next two with $50 \%$ of cooling and others with $100 \%$ of cooling fans. The samples were printed with the print head temperature equaled to $215^{\circ} \mathrm{C}$ and temperature of the heat bed of $70^{\circ} \mathrm{C}$. The $95 \%$ of material flow was used in the process.

ABS - acrylonitrile butadiene styrene is a popular thermoplastic polymer. In contrast to PLA, ABS has a much higher shrinkage factor. As a result, ABS requires much higher temperature on the heat bed. In the printing process ABS by Wolfix company was used. The density of ABS is approximately $1.08 \mathrm{~g} / \mathrm{cm}^{3}$. The tolerance of the filament diameter is the same as for PLA and equals $\pm \varnothing 0.05 \mathrm{~mm}$ but the roundness is $\pm 0.02 \mathrm{~mm}$. The recommended temperature of the hot end is in the range $230 \div 270^{\circ} \mathrm{C}$. ABS also requires using the heated bed and its temperature should be around $100^{\circ} \mathrm{C}$ [4]. ABS has a higher shrinkage factor than PLA so it requires low level of cooling. During the preparation of the samples, the percentage of cooling fans was set to $15 \%$. The hot end temperature was $250^{\circ} \mathrm{C}$ for all layers and the temperature of the heat bed was $100^{\circ} \mathrm{C}$ for first layer and $95^{\circ} \mathrm{C}$ for other layers. The material flow was $99 \%$. Due to the high shrinkage of the material, the heat chamber is found very useful to prevent deformation or warping.

PET - poly (ethylene terephthalate) is a common thermoplastic polymer. It provides outstanding resistance to weather conditions. When it is exposed to UV light it does not deform or lose its color. PET has unique properties of the adhesion. It adheres well to the heating table and has a low thermal shrinkage factor. PET is odorless during printing. In the printing process PET by EFilament3D Company was used. The density of PET is approximately $1.38 \mathrm{~g} / \mathrm{cm}^{3}$. The tolerance of the filament diameter and the roundness are not specified by the manufacturer. The only data given by the manufacturer are recommended temperatures. So, the temperature of the print head should be approximately $230^{\circ} \mathrm{C}$ and the temperature of the heat bed more than $60^{\circ} \mathrm{C}$ [4]. PET has an average shrinkage factor, that is why $50 \%$ of cooling was used starting from the fourth printed layer. The temperature of the print head was equal to $232^{\circ} \mathrm{C}$ on the first layer and $230^{\circ} \mathrm{C}$ for the others. The temperature of the heat bed was $75^{\circ} \mathrm{C}$ on the first layer and $73^{\circ} \mathrm{C}$ on others. $97 \%$ of material flow was used. 
PMMA - poly (methyl methacrylate) is a transparent thermoplastic material which is also known as acrylic glass or Plexiglas. The shrinkage factor for PMMA is similar to that of ABS that is why PMMA requires the heated bed. In order to prepare the samples, PMMA made by Spectrum Filaments Company was used. The density of PMMA is approximately 1.18 $\mathrm{g} / \mathrm{cm}^{3}$. PMMA has scratch resistance, high temperature resistance, high weather resistance, the sustainability of printing process and high quality of the printout. It transmits UV light, and some sources report that PMMA can be a replacement of glass. The tolerance of the filament diameter is equal to $\pm \varnothing 0.05 \mathrm{~mm}$ but the roundness is not specified by the manufacturer. The recommended temperature of the hot end is between 240 and $255^{\circ} \mathrm{C}$. The temperature of the heat bed should be between 80 and $90^{\circ} \mathrm{C}$ [4]. PMMA has as high shrinkage factor as $\mathrm{ABS}$ so the percentage of cooling was set to $15 \%$. The temperature of the print head was equal to $250^{\circ} \mathrm{C}$ and the temperature of heat bed was $95^{\circ} \mathrm{C}$ on the first layer and $90^{\circ} \mathrm{C}$ on other layers. $98 \%$ of material flow was used.

ASA - acrylonitrile styrene acrylate (ASA) is also a thermoplastic material. It is an alternative to ABS because ASA has better weather resistance than ABS. Because of UV light resistance, ASA is a very good option for printouts for outdoor use. It also has a low level of yellowing. This feature is very helpful when the printout needs to be used for a long time. In order to prepare the samples, ASA made by Fillamentum Company was used. The density of ASA is approximately $1.07 \mathrm{~g} / \mathrm{cm}^{3}$. The tolerance of the filament diameter is equal to $\pm \varnothing 0.05 \mathrm{~mm}$ but the roundness is not specified by the manufacturer. The melt volume index is $6 \mathrm{~cm}^{2} / 10 \mathrm{~min}$. The melting temperature is between 220 and $250^{\circ} \mathrm{C}$, but the recommended temperature of the hot end is between 250 and $255^{\circ} \mathrm{C}$. The temperature of heat bed should be between 90 and $100^{\circ} \mathrm{C}$. The shrinkage factor is between 0.3 and $0.6 \%$ [4]. ASA has similar printing settings as ABS. The temperature of the print head was $250^{\circ} \mathrm{C}$ and the temperature of heat bed was $100^{\circ} \mathrm{C}$ for first layer and $95^{\circ} \mathrm{C}$ for other layers. The percentage of cooling was equal to $15 \%$ and the material flow was at $97 \%$. During the tests 3DGence ONE 3D printer was used. The open filament policy is the most important feature in 3D printers. This allows to use different materials which are manufactured an especially for FDM printers. $3 \mathrm{DGence}$ ONE is used in rapid prototyping, manufacturing small and batch production.

\section{The tensile test results}

In each case the five samples for each filament material type were subjected to the tensile tests. The tensile test results achieved for 3DGO Wood filament material both in the Figure 1 and Table 1 are presented. Two marginal samples were rejected. Other correct samples have the following numbers: 3, 4 and 5. The value of the peak stress is between 16.6 and 16.9 $\mathrm{MPa}$. The value of the strain at peak stress is between 3.5 and 3.8\%. The value of the Young's modulus is between 794 and $797 \mathrm{MPa}$.

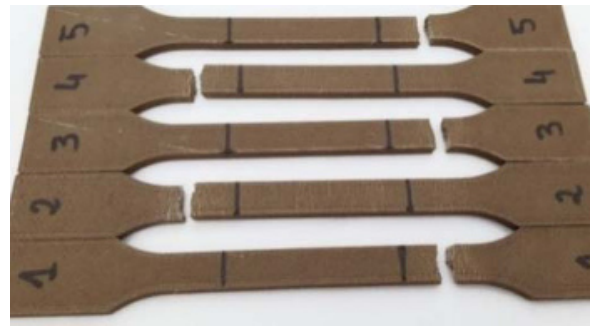

Fig. 1. 3DGO Wood - results of tensile tests.
Table 1. Tensile test data for 3DGO Wood.

\begin{tabular}{|c|c|c|c|c}
\hline No. & $\begin{array}{c}\text { Peak load } \\
{[\mathrm{N}]}\end{array}$ & $\begin{array}{c}\text { Peak } \\
\text { stress } \\
{[\mathrm{MPa}]}\end{array}$ & $\begin{array}{c}\text { Strain at } \\
\text { peak stress } \\
{[\%]}\end{array}$ & $\begin{array}{c}\text { Modulus } \\
{[\mathrm{MPa}]}\end{array}$ \\
\hline 1 & 646.487 & 16.2 & 3.2 & 793.015 \\
\hline 2 & 685.611 & 17.1 & 5.3 & 812.715 \\
\hline 3 & 664.899 & 16.6 & 3.5 & 794.841 \\
\hline 4 & 674.762 & 16.9 & 3.8 & 797.109 \\
\hline 5 & 671.824 & 16.8 & 3.5 & 794.333 \\
\hline
\end{tabular}

For PLA all samples were printed with high quality. The tested samples are presented in Figure 2. The same as for 3DGO Wood, all the samples were broken out of the working 
section. None discoloration can be seen near the breaking points. All collected parameters for PLA are presented in Table 2. The two extrema results were rejected. Other correct samples have the following numbers: 3, 4 and 5. The value of the peak stress is between 38 and $38.4 \mathrm{MPa}$. The value of the strain at peak stress is between 5 and $5.3 \%$. The value of the Young's modulus is between 1074 and $1100 \mathrm{MPa}$.

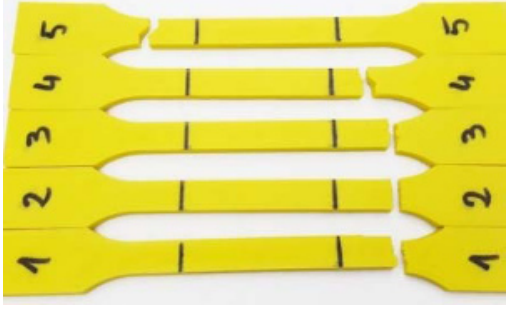

Fig. 2. PLA - results of tensile tests.

Table 2. Tensile test data for PLA.

\begin{tabular}{|c|c|c|c|c|}
\hline No. & $\begin{array}{c}\text { Peak load } \\
{[\mathrm{N}]}\end{array}$ & $\begin{array}{c}\text { Peak } \\
\text { stress } \\
{[\mathrm{MPa}]}\end{array}$ & $\begin{array}{c}\text { Strain at } \\
\text { peak stress } \\
{[\%]}\end{array}$ & $\begin{array}{c}\text { Modulus } \\
{[\mathrm{MPa}]}\end{array}$ \\
\hline 1 & 1461.407 & 36.5 & 4.9 & 1081.730 \\
\hline 2 & 1724.771 & 43.1 & 5.0 & 1228.285 \\
\hline 3 & 1537.018 & 38.4 & 5.3 & 1086.438 \\
\hline 4 & 1518.917 & 38.0 & 5.0 & 1100.184 \\
\hline 5 & 1530,403 & 38,3 & 5,3 & 1074,699
\end{tabular}

ABS is the difficult material to print. All samples were printed with high quality. Tested samples are presented in Figure 3. Unfortunately, all the samples were broke out of the working section. Distinct discoloration can be seen near the breaking points. All collected parameters for ABS are presented in table 3. Two marginal samples were rejected. Other correct samples have the following numbers: 1,2 and 5 . The value of the peak stress is between 34.6 and $35 \mathrm{MPa}$. The value of the strain at peak stress is between 5.5 and $5.6 \%$. The value of the Young's modulus is between 856 and $864 \mathrm{MPa}$.

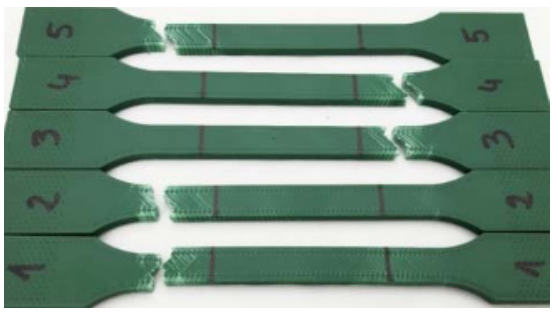

Fig. 3. ABS - results of tensile tests.
Table 3. Tensile test data for ABS.

\begin{tabular}{|c|c|c|c|c|}
\hline No. & $\begin{array}{c}\text { Peak load } \\
{[\mathrm{N}]}\end{array}$ & $\begin{array}{c}\text { Peak } \\
\text { stress } \\
{[\mathrm{MPa}]}\end{array}$ & $\begin{array}{c}\text { Strain at } \\
\text { peak stress } \\
{[\%]}\end{array}$ & $\begin{array}{c}\text { Modulus } \\
{[\mathrm{MPa}]}\end{array}$ \\
\hline 1 & 1461.407 & 36.5 & 4.9 & 1081.730 \\
\hline 2 & 1724.771 & 43.1 & 5.0 & 1228.285 \\
\hline 3 & 1537.018 & 38.4 & 5.3 & 1086.438 \\
\hline 4 & 1518.917 & 38.0 & 5.0 & 1100.184 \\
\hline 5 & 1530,403 & 38,3 & 5,3 & 1074,699
\end{tabular}

PET is a little bit harder to print than PLA. All samples were printed with high quality. Tested samples are presented in Figure 4. Surprisingly, three samples broke in the working section. The cross-sections of the tested samples are very homogeneous. All collected parameters for PET are presented in Table 4. Two marginal samples were rejected. Other correct samples have the following numbers: 1,4 and 5 . The value of the peak stress is between 49 and $51.1 \mathrm{MPa}$. The value of the strain at peak stress is between 7.8 and $8.1 \%$. The value of the Young's modulus is between 909 and $933 \mathrm{MPa}$. 


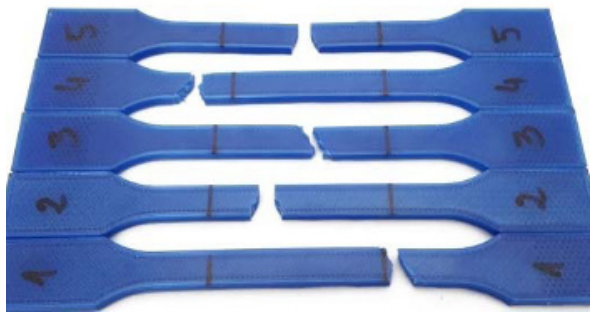

Fig. 4. PET - results of tensile tests.
Table 4. Tensile test data for PET.

\begin{tabular}{|c|c|c|c|c|}
\hline No. & $\begin{array}{c}\text { Peak load } \\
{[\mathrm{N}]}\end{array}$ & $\begin{array}{c}\text { Peak } \\
\text { stress } \\
{[\mathrm{MPa}]}\end{array}$ & $\begin{array}{c}\text { Strain at } \\
\text { peak stress } \\
{[\%]}\end{array}$ & $\begin{array}{c}\text { Modulus } \\
{[\mathrm{MPa}]}\end{array}$ \\
\hline 1 & 1960.23 & 49.0 & 7.8 & 909.99 \\
\hline 2 & 1697.86 & 42.4 & 6.9 & 846.17 \\
\hline 3 & 2052.73 & 51.3 & 8.1 & 927.84 \\
\hline 4 & 2033.92 & 50.8 & 8.0 & 928.32 \\
\hline 5 & 2044.39 & 51.1 & 8.1 & 933.51 \\
\hline
\end{tabular}

PMMA is one of the hardest materials to print. All samples were printed with good quality. Tested samples are presented in Figure 5. Surprisingly, sample no. 5 has three breaks and sample no. 2 has two breaks. Three samples broke in the working section. The crosssections of the tested samples are not so homogeneous. All collected parameters for PMMA are presented in Table 5. Two marginal samples were rejected. Other correct samples have the following numbers: 1,3 and 4 . The value of the peak stress is between 54.3 and $56 \mathrm{MPa}$. The value of the strain at peak stress is between 5.3 and 5.5\%. The value of the Young's modulus is between 1355 and $1376 \mathrm{MPa}$.

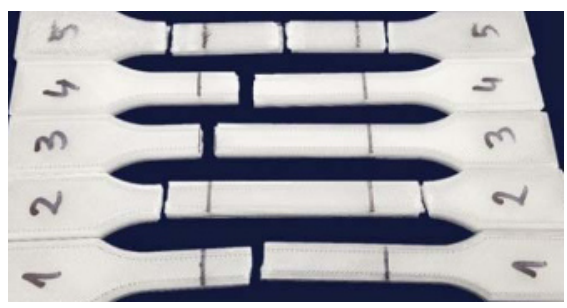

Fig. 5. PMMA - results of tensile tests.
Table 5. Tensile test data for PMMA.

\begin{tabular}{|c|c|c|c|c|}
\hline No. & $\begin{array}{c}\text { Peak } \\
\text { load [N] }\end{array}$ & $\begin{array}{c}\text { Peak } \\
\text { stress } \\
{[\mathrm{MPa}]}\end{array}$ & $\begin{array}{c}\text { Strain at } \\
\text { peak stress } \\
{[\%]}\end{array}$ & $\begin{array}{c}\text { Modulus } \\
{[\mathrm{MPa}]}\end{array}$ \\
\hline 1 & 2240.664 & 56.0 & 5.3 & 1376.651 \\
\hline 2 & 2329.248 & 58.2 & 5.9 & 1366.475 \\
\hline 3 & 2183.541 & 54.6 & 5.4 & 1360.051 \\
\hline 4 & 2171.132 & 54.3 & 5.5 & 1355.035 \\
\hline 5 & 2156.152 & 53.9 & 5.2 & 1349.742 \\
\hline
\end{tabular}

ASA is as hard to print as ABS. All samples were printed with high quality. Unfortunately, all the samples broke out of the working section. Slight discoloration can be seen near the breaking points. All collected parameters for ASA are presented in Table 6 . Two marginal samples were rejected. Other correct samples have the following numbers: 1 , 3 and 5. The value of the peak stress is between 31.8 and $32.1 \mathrm{MPa}$. The value of the strain at peak stress is between 7.1 and $7.9 \%$. The value of the Young's modulus is between 663 and $684 \mathrm{MPa}$.

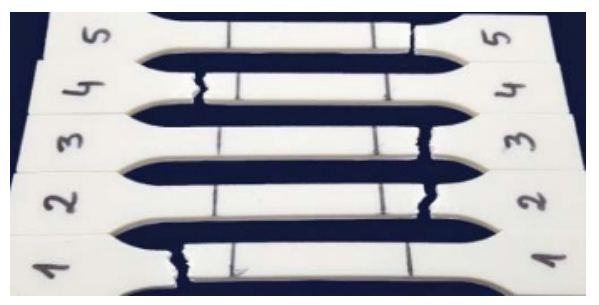

Fig. 6. ASA - results of tensile tests.
Table 6. Tensile test data for ASA.

\begin{tabular}{|c|c|c|c|c|}
\hline No. & $\begin{array}{c}\text { Peak } \\
\text { load [N] }\end{array}$ & $\begin{array}{c}\text { Peak } \\
\text { stress } \\
{[\mathrm{MPa}]}\end{array}$ & $\begin{array}{c}\text { Strain at } \\
\text { peak } \\
\text { stress } \\
{[\%]}\end{array}$ & $\begin{array}{c}\text { Modulus } \\
{[\mathrm{MPa}]}\end{array}$ \\
\hline 1 & 1285.697 & 32.1 & 7.9 & 684.363 \\
\hline 2 & 1299.721 & 32.5 & 8.3 & 678.889 \\
\hline 3 & 1270.319 & 31.8 & 7.2 & 663.789 \\
\hline 4 & 1260.193 & 31.5 & 7.2 & 667.619 \\
\hline 5 & 1276.971 & 31.9 & 7.1 & 679.332 \\
\hline
\end{tabular}




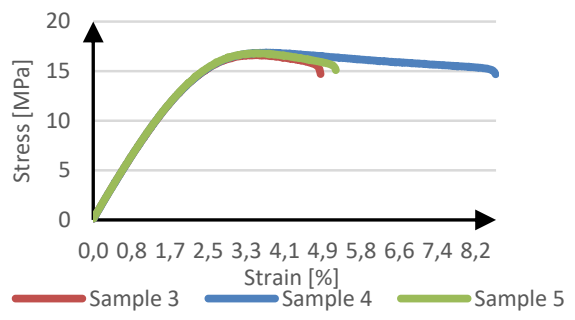

Fig. 7. Stress-strain diagram - Wood.

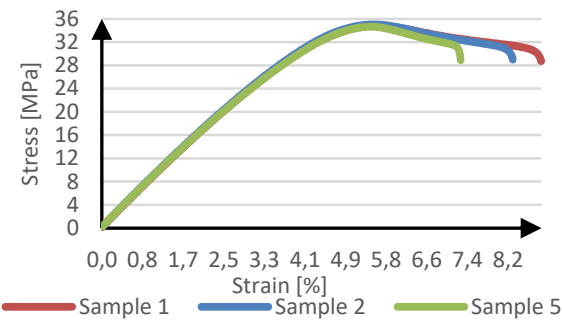

Fig. 9. Stress-strain diagram - ABS.

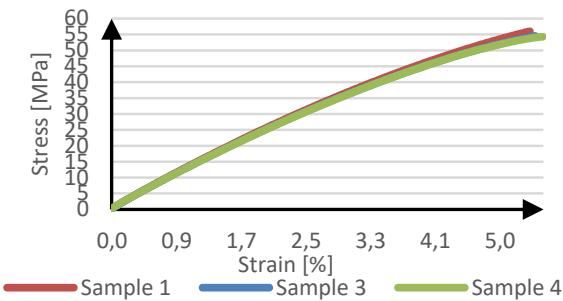

Fig. 11. Stress-strain diagram - PMMA.

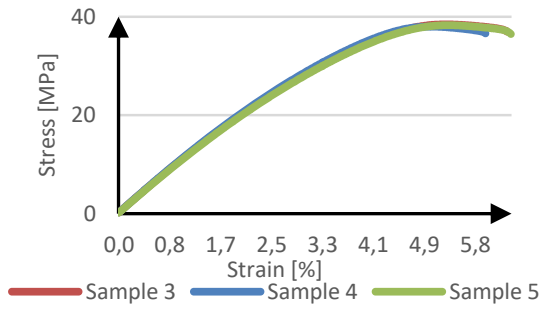

Fig. 8. Stress-strain diagram - PLA.

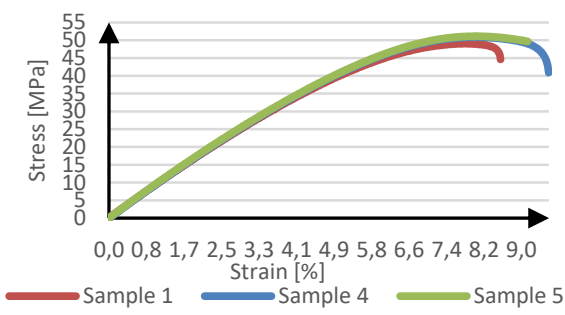

Fig. 10. Stress-strain diagram - PET.

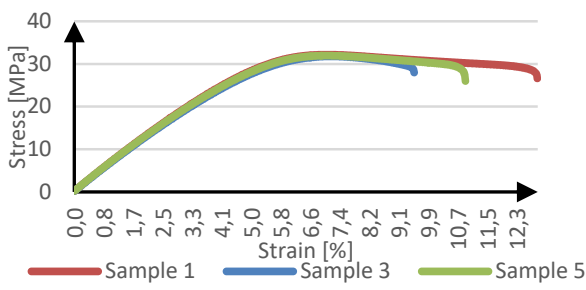

Fig. 12. Stress-strain diagram - ASA.

\section{Conclusion}

According to the research the weakest material is 3DGO Wood which has almost twice lower mechanical properties compared to ASA. Comparison of the most popular materials such as PLA and ABS is very interesting. It turns out that PLA has bigger average peak stress than ABS. On the other hand, ABS has a lower value of average Young's modulus which means that ABS is softer than PLA. ASA can be compared to a softer version of ABS, but the difference is small. The strongest material, presented in the ranking, is PMMA. Although PET is not as fragile as PMMA, it has a very good impact resistance. Also, due to the ease of printing, PET is the best choice for tough applications.

\section{References}

1. https://3dprintingindustry.com/news/journey-laywoo-d3-interview-wood-filamentinventor-kai-parthy-23357/

2. http://3dgo.pl/pl/p/3DGO-WOOD-500g-1\%2C75mm/79

3. https://spectrumstore.pl/pl/p/Filament-PMMA-1.75mm/106

4. http://3dfilamenty.com/pl/c/Filamenty/19 